$\underline{\text { Research Article }}$

\title{
Effectiveness of Nursing Intervention Package on Improving Bone Health among Post Menopausal Women Residing In Rural Villages of Tiruvannamalai District, Tamilnadu Pilot Study Report
}

\author{
Authors \\ Mr. Poova Ragavan', Dr S. Ani Grace Kalaimathi ${ }^{2}$, Prof. A.F.Annie Raja ${ }^{3}$, \\ Dr Anitha Babu ${ }^{4}$ \\ ${ }^{1}$ M.Sc., (N). PhD, Scholar MAHER University, Tamilnadu \\ ${ }^{2}$ Registrar, TNNMC, Chennai \\ ${ }^{3}$ Principal, St.Isabel college of Nursing, Chennai \\ ${ }^{4}$ Principal, Rajalakshmi College of Nursing, Chennai.
}

\begin{abstract}
International osteoporosis foundation in India suggests that nearly 50\% of all the hospital cases, $15 \%$ of fracture admissions are due to osteoporosis. In India number of osteoporotic patients approximately 26 million. Studies among Indian women aged 30-60 yrs from low income group bone mineral density at all the skeletal sites were much lower than values reported from the developed countries. The main aim of the study is to assess the Bone Mineral Density (bone health) among post menopausal women residing at selected rural community, tiruvannamalai district Tamil Nadu. The sample from the selected rural community and the research design used for this study was basic true experimental design - pre and post test design. The sample size selected for this study consists of 30 rural women 45-65 years of age from selected rural community at thenmudiyanur village tiruvannamalai district. Multi stage sampling technique was used to select the samples. The tool used in this study was Bone Mineral Density level by using bone densitometer to assess the post menopausal women. The data analysis was done using both descriptive and inferential statistics. This study clearly indicates that the nursing interventional package to the post menopausal women (low mineral density) in the experimental group had significant improvement in their post test level bone mineral density than the clients in the control group who had undergone normal home routine care women reversely increasing risk of complication like osteoporosis.

Keywords: Post Menopausal Women, BMD, Rural Community Women.
\end{abstract}

\section{Introduction}

Postmenopausal women play a vital role in the family and society in the world. Women over the age of 50 in particular face an increasing burden of responsibilities. One in three women over the age of 50 will suffer a menopausal problems that lead to fracture caused by osteoporosis.
Osteoporosis becomes a serious health issues for women aging process. Postmenopausal women high are predisposing them to an increased risk of fracture and other complication.

There is a direct relationship between the lack of estrogen after menopause and the development of osteoporosis. After menopause, bone resorption 
(breakdown) outpaces the building of new bone. Early menopause (before age 45) and any prolonged periods in which hormone levels are low and menstrual periods are absent or infrequent can cause loss of bone mass.

Low bone mineral density is not the cause of death but the complication develops due to the life style modification. Low bone mineral density patients are potentially candidate for many complications like Osteoporosis, hip fracture, vertebral disk fracture and recurrent fracture. Studies have been reported that diet and exercise programs for postmenopausal women that aimed to increase bone mineral density level (BMD) bone health care is positively associated with an increase in BMD in older adults. Intake of calcium diet and aerobic exercise and weight-bearing activity are important in maintaining overall bone health, strengthens of bone can reduce the risk of complications for post menopausal women.

\section{Statement of the Problem}

A study to assess the effectiveness of nursing intervention package on improving bone health among post menopausal women residing in rural villages of tiruvannamalai district.

\section{Objectives}

[E] To assess the pre and post test level of Bone health (Bone Mineral Density) among post menopausal women in experimental and control group.

To compare the pre test and post test level of Bone health (Bone Mineral Density) among post menopausal women in Experimental group and Control group.

$\mathbb{E} \square$ To compare the pre test and post test level of Bone health (Bone Mineral Density) among post menopausal women between Experimental group and Control group.

\section{Null Hypotheses}

$\mathrm{NH}_{1}$ : There will be no significant difference between pre and post test level of Bone health (bone mineral density) among post menopausal women within experimental and control group at
$\mathrm{P}<0.05$ level.

$\mathrm{NH}_{2}$ : There will be no significant difference between pre and post test level of Bone health (bone mineral density) among post menopausal women between experimental and control group at $\mathrm{P}<0.05$ level.

$\mathrm{NH}_{3}$ : There will be no significant a associate the pre and post test mean difference level of the bone health (bone mineral density) among post menopausal women with their selected demographic variables in experimental and control group at $\mathrm{P}<0.05$ level.

\section{Research Methodology}

Research Design: Basic experimental design which comes under True experimental design. (Pretest - posttest only design)

Independent Variable: Nursing intervention package on bone health

Dependent Variable: Bone health among post menopausal women

Setting of the study: The study was conducted who is residing in thenmudiyanur village of Thiruvannamalai District.

Population: The populations included in the study are post menopausal women residing in thenmudiyanur rural villages of Tiruvannamalai District, Tamil nadu.

Sample: Sample is consist of post menopausal women

Sample Size: The sample size in the study 30 post menopausal women (15 experimental groups and 15 control group)

Sampling Technique: Multi stage sampling technique was used to select the 30 post menopausal women with low bone mineral density level.

\section{Criteria of Sample Collection \\ Inclusion criteria}

Age group between 45 to 65 years.

Post menopausal women with after two years

Post menopausal women who have low bone mineral density ( -1 to $-3 \mathrm{SD})$. 
Who can understand Read and speak the Tamil language.

Post menopausal women who are willing to participate in the study.

\section{Exclusion criteria}

Post menopausal women who are taking steroid drugs, HRT drugs.

Post menopausal women who are prior case of removal of uterus /ovary

Post menopausal women who are hypoparathyroidism, chrons disease.

Post menopausal women who are with physical disability.

\section{Data Collection Tool}

\section{Data collection tool consists of two parts}

Part -A: Consists of selected demographic variables such as age, height, weight, BMI, Educational status, monthly income and dietary pattern, etc.

Part- B: Assessment of Bone Mineral Density level by using bone densitometer

\section{Modified Bone Density Levels}

80 Normal - Bone density is within 1 SD $(+1$ or -1 ) of the young adult mean.

so Low bone mass (Osteopenia) - Bone density is between 1 and 2.5 SD below the young adult mean ( -1 to $-2.5 \mathrm{SD})$.

80 Osteoporosis - Bone density is between $2.5 \mathrm{SD}$ to $-3.0 \mathrm{SD}$ young adult mean.

(o) Severe (established) osteoporosis - Bone density is more than 3.0 SD young adult mean, and there have been one or more osteoporotic fractures.

\section{Data Collection Procedure}

The formal permission for conducting study was obtained from the village administrative officer in thenmudiyanur village Tiruvannamalai. The study period was 3 month. The investigator selected sample by using multi stage sampling technique method. The investigator explained about the aims, purpose, advantages of the study to the experimental group and control group. After obtaining the demographic details, Investigator checked bone density level by using ultrasound bone densitometer $(\mathrm{CM}-200)$ for 90 participants. Investigator selected low bone density level for 15 subjects were assigned to experimental group and 15 subjects assigned to control group. The investigator made awareness about post menopausal women regarding bone health (Exercise, Diet \& prevention) and demonstrated about post menopausal exercise, supplementation of calcium rich diet among experimental group subjects. After post test awareness program was conducted in control group.

\section{Results and Discussion}

First objectives were to assess the pre and post test level of Bone health (Bone Mineral Density) among post menopausal women in experimental and control group.

Frequency and percentage distribution of pretest and post test level of bone health among post menopausal women in experimental and control group. The analysis on pretest level of bone mineral density in experimental group, revealed that $14(93.3 \%)$ had osteopenia and $1(6.7 \%)$ had osteoporosis. The analysis on posttest level of bone mineral density in experimental group, revealed that $11(73.3 \%)$ had osteopenia and 4(93.3\%) had normal bone density level. The analysis on pretest level of bone mineral density in control group, revealed that 14(93.3\%) had osteopenia and 1(6.7\%) had osteoporosis. The analysis on posttest level of bone mineral density in control group, revealed that had $8(53.3 \%)$ had osteopenia and 7(46.7\%) had osteoporosis.

Second objective were to compare the pre test and post test level of Bone health (Bone Mineral Density) among post menopausal women in Experimental group and Control group.

In Experimental group, the pretest mean value of bone mineral density was 1.92 with S.D 0.40 and the posttest mean value was 1.63 with S.D 0.52. The calculated paired' value $\mathrm{t}=3.339$ was found to be statistically significant at $p<0.05$ level. In control group, the pre test mean value of bone mineral density was 1.88 with S.D 0.35 and the 
post test mean value was 2.23 with S.D 0.54. The calculated paired' value $\mathrm{t}=2.948$ was statistically significant at $\mathrm{p}<0.05$ level.

Third objectives were to compare the pre test and post test level of Bone health (Bone Mineral Density) among post menopausal women between Experimental group and Control group.

The pretest mean value degree of wound of bone mineral density in Experimental group was 1.92 with S.D 0.40 and the pretest mean value of bone mineral density in control group was 1.88 with S.D 0.35 . The calculated unpaired' value $\mathrm{t}=0.266$ was found to be statistically not significant. The post test mean value degree of bone mineral density in Experimental group was 1.63 with S.D 0.52 and the post test mean value degree of bone mineral density in control group was 2.23 with S.D 0.54 . The calculated unpaired' value $\mathrm{t}=3.075$ was statistically significant at $\mathrm{p}<0.05$ level.

\section{Conclusion}

The present study evaluated the effectiveness of Nursing interventions package on bone health related post menopausal women, For the purpose the study was of assessing bone mineral density level related post menopausal women, tool was used for the study was reliable and feasible of the study. This study clearly indicates that the nursing interventional package to the post menopausal women (low mineral density) in the experimental group had significant improvement in their post test level bone mineral density than the clients in the control group who had undergone normal home routine care women reversely increasing risk of complication like osteoporosis.

\section{Acknowledgment}

The authors thank to Dr. S. Vijayalakshmi. Principal. Vignesh Nursing College, Tiruvannamalai. For her constant motivation, support, valuable guidance and direction, appropriate suggestions for completion of this study in all respect under her command.

\section{Bibliography}

1. Sambrook P, Kelly P, Eisman J. Bone mass and ageing. Baillieres Clin Rheumatol. Oct 1993;7(3):445-457.

2. Khosla S, Oursler MJ, Monroe DG. Estrogen and the skeleton. Trends Endocrinol Metab. Nov 2012;23(11):576581.

3. Christiansen C, Christensen MS, Larsen NE, Transbol IB. Pathophysiological mechanisms of estrogen effect on bone metabolism. Dose-response relationships in early postmenopausal women. J Clin Endocrinol Metab. Dec 1982;55(6):11241130.

4. Richelson LS, Wahner HW, Melton LJ, 3rd, Riggs BL. Relative contributions of aging and estrogen deficiency to postmenopausal bone loss. N Engl J Med. Nov 15 1984;311(20):1273-1275.

5. Clark EM, Gould VC, Morrison L, Masud $\mathrm{T}$, Tobias J. Determinants of fracture risk in a UK-population-based cohort of older women: a cross-sectional analysis of the Cohort for Skeletal Health in Bristol and Avon (COSHIBA). Age Ageing. Jan 2012;41(1):46-52.

6. Sambrook P, Cooper C. Osteoporosis. Lancet. Jun 17 2006;367(9527):20102018.

7. Doherty DA, Sanders KM, Kotowicz MA, Prince RL. Lifetime and five-year agespecific risks of first and subsequent osteoporotic fractures in postmenopausal women. Osteoporos Int. 2001;12 (1):1623. 